\title{
Mariolina Bertini, Honoré de Balzac: gli scritti teorici
}

\section{Marco Stupazzoni}

\section{(2) OpenEdition}

\section{Journals}

\section{Edizione digitale}

URL: http://journals.openedition.org/studifrancesi/5386

DOI: $10.4000 /$ studifrancesi.5386

ISSN: 2421-5856

\section{Editore}

Rosenberg \& Sellier

\section{Edizione cartacea}

Data di pubblicazione: 1 dicembre 2016

Paginazione: $544-545$

ISSN: 0039-2944

\section{Notizia bibliografica digitale}

Marco Stupazzoni, « Mariolina Bertini, Honoré de Balzac: gli scritti teorici », Studi Francesi [Online], 180

(LX | III) | 2016, online dal 01 janvier 2017, consultato il 18 septembre 2020. URL : http://

journals.openedition.org/studifrancesi/5386 ; DOI : https://doi.org/10.4000/studifrancesi.5386

\section{Questo documento è stato generato automaticamente il 18 settembre 2020.}

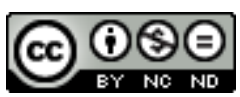

Studi Francesi è distribuita con Licenza Creative Commons Attribuzione - Non commerciale - Non opere derivate 4.0 Internazionale. 


\title{
Mariolina Bertini, Honoré de Balzac: gli scritti teorici
}

\author{
Marco Stupazzoni
}

\section{NOTIZIA}

MARIOLINA BERTINI, Honoré de Balzac: gli scritti teorici, in I cadaveri nell'armadio. Sette lezioni di teoria del romanzo, a cura di Gabriella вosco e Roberta Sapino, Torino, Rosenberg \& Sellier, 2015, «Biblioteca di Studi Francesi», pp. 53-73.

1 L'esigenza critica e metodologica di superare l'ormai ossidata contrapposizione tra i due più rilevanti modelli esegetici riguardanti la poetica letteraria di Balzac costituisce, per Mariolina Bertini, la condizione indispensabile per riconsiderare, con maggiore equilibrio e consapevolezza, la portata della riflessione teorica dello scrittore francese sull'arte del romanzo. Sarebbe, infatti, riduttivo comprimere in una formula unica ed univoca la varietà e la pluralità di un universo di idee così multiforme e frastagliato quale è stato il pensiero di Balzac lungo la strada del romanzo. Insistere, in maniera unilaterale, sul carattere coerente e unitario dell'estetica balzachiana, oppure, al contrario, sulla sua natura versatile e multiforme significa non riconoscere, in Balzac, il rifiuto per ogni forma di chiusura e di fissità del pensiero.

2 In questo studio, l'A. ripercorre cronologicamente le trasformazioni della poetica di Balzac a partire dalle opere giovanili mettendole in costante relazione con la storia del romanzo - in quanto genere letterario - nella prima metà dell'Ottocento.

A partire dalla fine degli anni venti del xIX secolo (1828: Avertissement du Gars), cominciano a delinearsi alcuni assunti fondamentali che determineranno non soltanto la genesi, ma l'evoluzione della teoria del romanzo in Balzac. La metafora del «miroir concentrique» associata all'importanza attribuita al dettaglio, sempre integrato in una visione unitaria sono alcuni tra i concetti fondamentali su cui si fonda, a giudizio di Balzac, il romanzo moderno. Tra il 1820 e il 1830, osserva l'A., «Balzac si fa portavoce dell'esigenza di un romanzo che si arricchisca, che non si limiti più alla psicologia e ai 
sentimenti, ma che interpreti i segni della vita sociale, incorpori l'erudizione storica, imiti il teatro e la pittura» (p. 63).

È in Illusions perdues che lo scrittore svilupperà in maniera chiara e pregnante la sua teoria del romanzo in uno dei momenti più autoriflessivi della Comédie humaine. Nelle parole di D'Arthez a Lucien, si riflette il modello balzachiano di romanzo inteso come struttura ciclica aperta e dinamica. Radicalmente opposta allo scritto giornalistico, l'opera letteraria, dirà Blondet allo stesso Lucien, non può considerarsi che doppia, plurale perché «tutto è bilaterale nel campo del pensiero». Studiare la poetica di Balzac, svelarne la ricchezza delle intuizioni e delle proposte significa, per l'A., «tener conto da un lato della continuità di un pensiero fortemente originale [...]; dall'altro, dell'importanza dei mille rivoli accidentali nei quali questo pensiero prende forma, reagendo di volta in volta a effimere mode culturali, a opere di particolare rilievo, a critiche ostili, a osservazioni sul ruolo sociale dell'artista» (p. 73). 